\title{
A apresentação de uma tragédia:
}

\section{uma reflexão sobre os efeitos de sentido observados na postura dos apresentadores do Jornal Nacional durante a cobertura do acidente com a Chapecoense}

Resumo: A tragédia ocorrida com o time brasileiro da Associação Chapecoense de Futebol chocou o mundo. A queda do avião que matou 71 pessoas foi noticiada pelos telejornais brasileiros desde as primeiras horas do dia 29 de novembro de 2016. Diante de acontecimento tão significativo, buscamos neste artigo explorar a notícia através da observação dos efeitos de sentido encontrados no discurso emitido pelos apresentadores do Jornal Nacional. Para isso, utilizaremos como base os princípios da Análise de Discurso (AD) de linha francesa, mapeando os elementos relacionados à ideologia, memórias e silêncios que estão presentes nos discursos pronunciados e interpretados por estes sujeitos, os apresentadores, na cobertura televisiva da tragédia.

Palavras-chave: Tragédia Chapecoense. Análise de Discurso. Apresentadores telejornalísticos. Jornal Nacional.

\section{La presentación de una tragedia:una reflexión a} respecto de los efectos de sentido observados en la atictude de los apresentadores del Jornal Nacional durante la cobertura del accidente con la Chapecoense

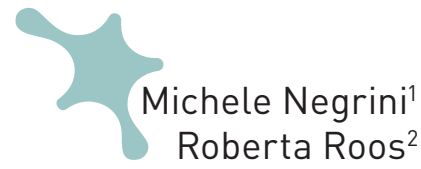

Jornalista. Mestre em Comunicação e Informação pela UFRGS. Doutora em Comunicação pela PUCRS. Pós-doutoranda na UFBA, no programa de Pós-

Graduação em Comunicação e Cultura Contemporâneas.

Professora da Universidade Federal de Pelotas. Integrante do núcleo de pesquisadores do Grupo Interinstitucional de Pesquisa em Telejornalismo (GIPTele).

2 Jornalista. Mestre em Educação pela UPF. Doutoranda em Comunicação na UFSM. Professora da Universidade Federal do Pampa - campus São Borja. Integrante do núcleo de pesquisadores do Grupo Interinstitucional de Pesquisa em Telejornalismo (GIPTele).

Resumen: La tragedia que se llevó a cabo con el equipo brasileño Chapecoense Asociación de Fútbol, sorprendió al mundo. El accidente de avión que mató a 71 personas fue reportado por los programas de noticias de Brasil desde las primeras horas del día 27 de noviembre de 2016. Frente a un evento tan importante, en este artículo se pretende explorar la noticia a través de la observación de los efectos de sentido que se encuentran en el discurso pronunciado por presentadores de Jornal Nacional. Basándose para esto, en el análisis de discurso (DA) de la línea francesa. Se tendrá en cuenta factores tales como la ideología, los recuerdos y silencios presentes en discursos e interpretados por estos sujetos, para la cobertura de la tragedia.

Palabras clave: Tragedia Chapecoense. Análisis de Discurso. Presentadores telejornalísticos. Jornal Nacional. 


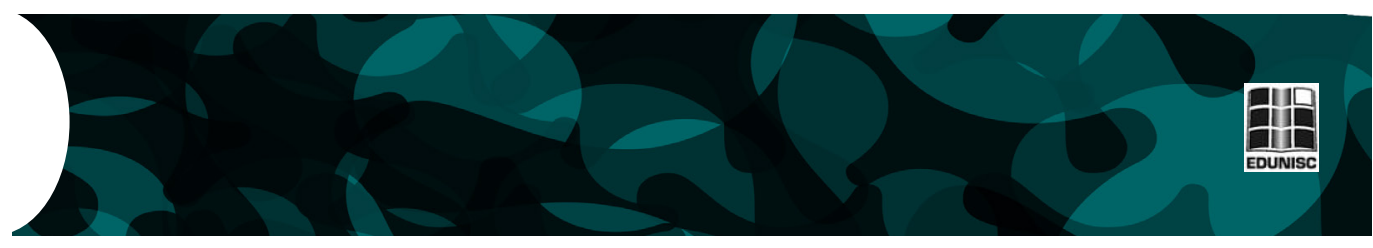

\title{
The presentation of a tragedy: reflecting on the sense effect observed on the posture of the Jornal Nacional's anchors during the coverage of the Chapecoense accident
}

\begin{abstract}
The tragedy, occurred with the Brazilian soccer team Associação Chapecoense de Futebol, shocked the world. The plane crash who killed 71 people was reported by the Brazilian news reports since the beginning of 2016 November, 27th. Facing the significant event, in this article we pursue to explore the News towards the sense observation found in the speech used by the presenters of Jornal Nacional. In order to do that, we used the principles of French Speech Analysis, observing the elements related to ideology, memory and silence presented in the pronounced and interpreted speeches by this presenters during the tragedy's coverage.
\end{abstract}

Keywords: Chapecoense. Speech Analysis. News report anchors. Jornal Nacional.

\section{Introdução}

No dia 29 de novembro de 2016, os brasileiros acordaram com a notícia de que o avião da empresa boliviana LaMia, que transportava o time da Associação Chapecoense de Futebol para a Colômbia, havia sofrido um acidente e caído nas proximidades do Aeroporto Internacional José Maria Córdova. A equipe disputaria a final da Copa Sul-Americana contra o Atlético Nacional.

O voo tinha 77 pessoas a bordo, entre elas a tripulação, jogadores da Chapecoense, comissão técnica e dirigentes, além de jornalistas designados para fazer a cobertura do evento esportivo para os veículos de comunicação brasileiros. Das 77 pessoas que estavam no avião, 71 morreram.

Com a chegada dos corpos ao Brasil, os membros da Chapecoense, como jogadores, dirigentes e integrantes da comissão técnica, receberam homenagens no estádio do time, aArena Condá, em Chapecó(SC). Acerimônia contou com a presença do presidente da República e de autoridades locais e colombianas. As vítimas também receberam homenagens na Colômbia. No dia 30 de novembro de 2016, data em que teria sido realizada a partida da final da Copa Sul-Americana, entre Chapecoense e Atlético Nacional, o Estádio Atanasio Girardot, em Medellín, foi palco de cerimônia de honra, reunindo milhares de pessoas.

Os meios de comunicação fizeram grandes coberturas do acidente que repercutiu no mundo todo. Os canais de TV acompanharam amplamente os fatos. Ao longo das coberturas, os telejornais fizeram reconstituições dos acontecimentos daquela noite e compartilharam com o público diversos aspectos relativos à tragédia, tais como a retirada dos corpos e dos sobreviventes do local da queda do avião, o estado de saúde dos sobreviventes nos hospitais, a reação dos familiares das vítimas no Brasil, a chegada das 
famílias à Colômbia, a presença de parentes e dirigentes do clube no estádio da Chapecoense, as manifestações na cidade de Chapecó e a repercussão da tragédia pelo mundo.

Outra pauta dos telejornais relacionou-se às possíveis explicações das causas da queda do avião. Como usualmente ocorre, especialistas em aviação foram fontes muito procuradas a fim de tentar esclarecer o ocorrido. As condições do avião, a quantidade de combustível que era carregada no voo fatal e o plano de voo foram alguns dos aspectos detalhados por jornalistas e fontes nos telejornais de todo o país.

Outro ponto que ficou evidente nas coberturas televisivas foi o resgate à memória dos espectadores das ocorrências de outros acidentes com equipes esportivas. Entre os casos estão: a queda do avião com a seleção uruguaia de rúgbi na Cordilheira dos Andes em 1972; a queda no mar de um avião da marinha peruana, em 1987, com mais de 40 pessoas mortas - entre elas, os jogadores de uma equipe de futebol do Peru; a explosão de um avião da Zâmbia, matando a seleção de futebol do país, em 1993; e um acidente aéreo ocorrido na Rússia, em 2011, que vitimou um time inteiro de hóquei.

O ótimo momento esportivo do time da Chapecoense e a alegria dos jogadores receberam ênfase na cobertura dos telejornais. Vídeos amadores feitos pelos atletas, no aeroporto, foram levados ao ar. E a comoção da torcida ganhou destaque. Os telejornais destacaram o fato de a Chapecoense estar vivendo o melhor momento de sua trajetória esportiva e também valorizaram a atitude do time colombiano, Atlético Nacional, de abrir mão do título em disputa para concedê-lo à equipe catarinense.

Os telejornais ainda exibiram as homenagens de times e atletas do Brasil e do exterior aos jogadores mortos. No acidente, 20 profissionais da área da comunicação também faleceram. Por isso, as perdas no campo do jornalismo, em decorrência da morte dessas pessoas, também foram repercutidas, lamentadas e ressaltadas nas coberturas.

Os telejornais da Rede Globo deram início à cobertura jornalística do caso desde as primeiras horas do dia 29 de novembro. O telejornal Hora Um, que vai ao ar a partir das $5 \mathrm{~h}$ da manhã, começou dando as primeiras notícias. O Jornal Hoje fez um amplo acompanhamento da tragédia, mostrando diversos pontos sobre a ocorrência. E o Jornal Nacional (JN), que é o objeto deste estudo, repercutiu os acontecimentos, que se deram durante todo o dia em relação à queda do avião, e seus desdobramentos, atualizando os espectadores acerca do fato. A cobertura do $\mathrm{JN}$ foi permeada pela exploração das emoções, tanto de familiares, como do público em geral. Na semana da tragédia, o JN foi apresentado por Giuliana Morrone e Heraldo Machado.

Ao chamarmos a atenção para os aspectos que identificamos de forma preliminar em relação à cobertura feita por telejornais sobre a tragédia com o avião da Chapecoense, e considerando a importância do Jornal Nacional no cenário televisivo brasileiro, destacamos a pertinência da observação desta cobertura neste fato específico. E realçamos também a relevância do papel dos apresentadores, no contexto do Jornal Nacional, para a condução do programa e para a produção de sentidos sobre os fatos. 
Desse modo, este estudo tem como foco a postura dos apresentadores do Jornal Nacional na cobertura da tragédia da Chapecoense, levando em consideração os discursos, a evidenciação da memória, a ideologia e os silenciamentos. Para isso, buscaremos apoio na Análise de Discurso de linha francesa, que prevê a força que a imagem tem na constituição do dizer, destacando o funcionamento da linguagem relacionada ao imaginário. Nas palavras de Orlandi (2012, p. 42), o imaginário "não 'brota' do nada: assenta-se no modo como as relações sociais se inscrevem na história e são regidas, em uma sociedade como a nossa, por relações de poder". A autora ressalta ainda que a explicitação do modo como os sentidos são produzidos é possível através da Análise do Discurso, que atravessa este imaginário condicionante dos sujeitos e suas discursividades. Para tanto, a prática voltase às investigações acerca dos discursos destes sujeitos (os apresentadores do JN), que estão carregados de ideologias, memórias e silêncios.

\section{Os apresentadores telejornalísticos}

A maioria dos apresentadores, nos primórdios do telejornalismo, tinha passagem pelo teatro e não era necessariamente jornalista. $\mathrm{O}$ importante era ter boa voz e aparência para evitar as distrações do telespectador.

Nessa época costumava ser sempre um homem, era reconhecido como personagem principal, o responsável pelo nível do programa, admirado, respeitado e objeto de constante interesse do público, dentro e fora das telas. Do outro, ele estava entre os últimos a serem consultados a respeito de conteúdo, estilo e formato. (YORK, 2006, p. 246).

Os apresentadores não tinham participação na formulação dos textos, apenas os interpretavam com a ajuda de teleprompter e ponto eletrônico, e isso não parecia ser digno de tantos méritos: "um apresentador chegou a dizer que isso não era tarefa de gente grande" (YORK, 2006, p. 246). Mas, a partir da década de 1980, as noções técnicas e profissionais foram sendo levadas em consideração, além da noção de que esta não era uma tarefa tão fácil como parecia. Destes profissionais esperava-se, além de boa pronúncia e dicção, a colaboração na produção textual e na execução de entrevistas durante o jornal. A função de apresentador, principalmente a partir dos anos 2000, como salienta York (2006), foi oferecida a profissionais com antecedentes jornalísticos (repórteres ou correspondentes), incentivados a participar das decisões editoriais. Essas alterações vieram da necessidade do apresentador conhecer mais a fundo as reportagens e matérias apresentadas no telejornal.

Fascínio e intimidade são duas características marcantes destes sujeitos. York (2006, p. 244) comenta a amplitude do nível de proximidade do apresentador com o telespectador através da seguinte afirmação: "pesquisas de opinião colocaram Walter Cronkite, apresentador do jornal da CBS durante a maior parte da segunda metade do século XX, como uma das pessoas mais confiáveis dos Estados Unidos". 
A responsabilidade por aquilo que é pronunciado é grande. Qualquer situação inesperada, como um engasgo, erro de pronúncia ou até mesmo uma tosse, pode abalar o sentido da notícia, elaborada através de um texto coloquial, com frases curtas e objetivas. Além disso, expressões faciais, como um levantar de sobrancelhas ou um silêncio maior do que o esperado, podem ser interpretadas como um comentário particular ou pessoal. Neste sentido, destacam-se as palavras de Orlandi (1996, p. 22): "o gesto de interpretação é o que - perceptível ou não para o sujeito e/ou para seus interlocutores - decide a direção dos sentidos".

Atualmente, as funções desempenhadas em uma emissora podem variar de acordo com sua abrangência. A figura do editor representa a palavra final na seleção daquilo que vai ao ar e de que forma deve ir; porém, este sujeito pode desempenhar apenas esta tarefa nos bastidores ou acumular função com a apresentação do telejornal, como é o caso da maioria dos apresentadores das emissoras de TV aberta no Brasil. Sobre isso, diz York (2006, p. 251): "da mesma forma que um apresentador ruim pode certamente destruir um bom script, um bom apresentador pode salvar um script ruim".

A contratação de profissionais certos, compatíveis com cada perfil de emissora, busca manter o público fiel ao telejornal. Para ser um apresentador televisivo, atualmente, é importante ter experiência jornalística acima de tudo. E, ao final deste processo, torna-se difícil avaliar o que é mais importante para a audiência: se é quem apresenta e a forma como o faz ou o que é mostrado/selecionado através do discurso do sujeito apresentador.

\section{Os apresentadores do Jornal Nacional}

O Jornal Nacional é um dos principais telejornais do Brasil. A primeira edição foi veiculada no dia $1^{\circ}$ de setembro de 1969 . E, segundo o site Memória Globo ${ }^{3}$, foi o primeiro telejornal do país a ser transmitido em rede nacional, competindo com o Repórter Esso, da Rede Tupi.

Concordamos com Fechine (2008) sobre o fato de a credibilidade de um telejornal ter ligações diretas com a confiança depositada pelo público nos apresentadores do programa. No decorrer de mais de 40 anos de história, o Jornal Nacional teve vários jornalistas no seu comando. Desde que foi ao ar, quatro mulheres foram apresentadoras titulares na bancada do JN: Lillian Witte Fibe, Fátima Bernardes, Patrícia Poeta e a atual, Renata Vasconcellos. E desde o surgimento do telejornal, cinco homens foram apresentadores titulares: Hilton Gomes, Cid Moreira, Sérgio Chapelin, Celso Freitas e atualmente, William Bonner. Além dos jornalistas fixos, outros profissionais exercem a função, cobrindo férias dos titulares e apresentando as edições de sábado.

Cabe destacar que o Jornal Nacional tem um padrão desde que entrou no ar: é apresentado por dois jornalistas, que estão sentados atrás de uma bancada. Na atualidade, um formato menos rígido pode ser observado: os apresentadores chegam a caminhar pelo estúdio e usam recursos tecnológicos para se comunicar, ao vivo, com jornalistas e correspondentes que estão em outros locais.
3 http://memoriaglobo.globo.com/ programas/jornalismo/telejornais/ jornal-nacional.htm 

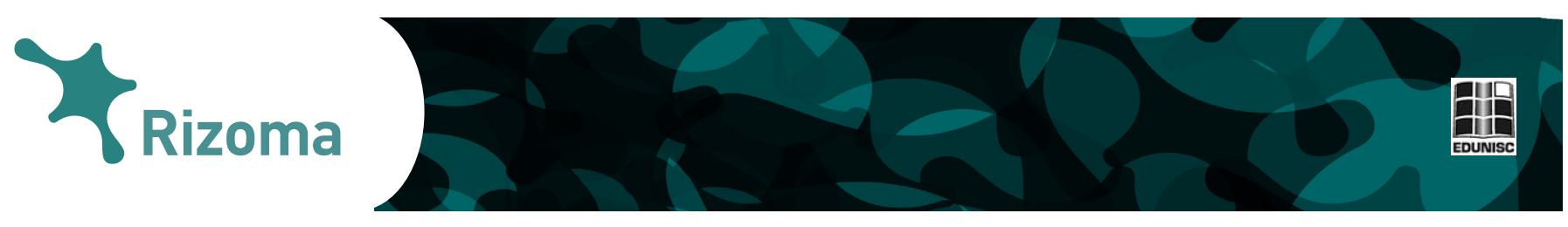

Em relação à presença dos apresentadores, na história do $\mathrm{JN}$, a primeira

${ }^{4}$ https://twitter.com/realwbonner dupla foi formada por Hilton Gomes e Cid Moreira. Podemos considerar como as duplas mais emblemáticas Sérgio Chapelin e Cid Moreira, e William Bonner e Fátima Bernardes. Os últimos, que agora são um excasal, chegaram a ser rotulados como o par mais famoso do telejornalismo brasileiro enquanto estavam juntos no ar.

Ao analisar a importância dos apresentadores para um telejornal, Fechine (2008, p.69) salienta que muitas mudanças no modo de atuar desses profissionais foram notadas no decorrer do processo histórico:

Do "locutor de notícias", que se limitava a ler as informações com atitude distanciada e em estilo radiofônico, ao "âncora", que se posiciona enfaticamente sobre os fatos noticiados, podemos observar, grandes transformações não somente nos papéis, mas nas posturas e perfis dos apresentadores de telejornal.

A autora destaca que, na atualidade, é comum verificar apresentadores de telejornais que se posicionam contra políticos e que cobram soluções para os problemas sociais, mostrando visões ideológicas. Ela acrescenta que há ainda os que assumem posturas mais descontraídas e fazem brincadeiras com o público ou com a própria produção, além de revelarem preferências individuais nos comentários sobre as reportagens. "Por meio de tais comportamentos, o apresentador passa, por um lado, a ser percebido paulatinamente pelo público como alguém mais próximo e familiar [...]" (FECHINE, 2008, p. 69).

No caso do Jornal Nacional, o apresentador William Bonner é conhecido pela interatividade com o público, por meio de seus constantes contatos pela rede social Twitter. ${ }^{4}$ Em relação a sua postura como jornalista, Bonner chegou a ser questionado pelos espectadores mais críticos em algumas ocasiões, como nas entrevistas com os presidenciáveis nas eleições de 2014. Já Renata Vasconcellos não gera tantas polêmicas, mas também é vista como figura relevante no $\mathrm{JN}$.

A partir da importância dos apresentadores no contexto do Jornal Nacional, é precípua a realização de um estudo sobre a postura e os discursos desses sujeitos na cobertura da tragédia com o time da Chapecoense.

\section{Discurso, memória e silêncio}

Os sentidos e seus efeitos aparecem no discurso de diversas formas. Quem fala ou quem escuta o faz de um lugar particular carregado de experiências, vivências, conhecimentos e expectativas. As condições de produção se estabelecem por meio das relações entre diferentes posiçõessujeitos. Sobre isso, Orlandi (1997, p. 15) explica que: "a palavra discurso, etimologicamente, tem em si a ideia de curso, de percurso, de correr por, de movimento". Cada discurso que se apresenta vem implicado por outros que se relacionam por antecedentes; em alguns momentos há consenso, em 
outros, confrontos. Portanto, o discurso é definido como "efeito de sentido entre interlocutores" (ORLANDI, 1997, p. 203).

Nessa perspectiva, reflete-se sobre os discursos pronunciados nos telejornais brasileiros, que são acompanhados por milhares de pessoas todos os dias. Os recortes de situações que são apresentadas na televisão levam em consideração o perfil editorial de cada emissora e são consumidos, na maioria das vezes, como a única versão dos fatos. O texto elaborado pelo apresentador ou repórter é constituído por elementos do repertório cultural destes sujeitos que, mesmo tentando trazer um discurso imparcial, manifestam, por meio dos silêncios, de ideologias e até das expressões faciais, posicionamentos particulares. Para Orlandi (2007, p. 40), "o texto não nasce nem morre em si mesmo, mas remete a outros discursos anteriores ou posteriores a ele, pois não há discurso que não se relacione com outros". As condições de produção dos discursos mantêm relações com falas pronunciadas, imaginadas ou até mesmo possíveis.

Muitos dos efeitos que aparecem nos discursos provêm de ideologias, visto que, segundo Orlandi (2005), as pessoas são filiadas a um saber discursivo que não se aprende, mas que se produz. O trabalho ideológico pode funcionar também, de acordo com Petri (2009), para que as diferenças não sejam aceitas como constitutivas, pois "vivemos numa sociedade de aparências. Cada vez mais valorizamos a imagem, a representação que se tem a partir de uma imagem ou de outra" (PETRI, 2009, p. 37).

Além dos efeitos ideológicos presentes nos discursos, neste caso referindo-se aos emitidos pelos apresentadores televisivos, está também a análise daquilo que não foi dito. O silêncio pode ser interpretado de diversas formas, como aponta Orlandi (2012, p. 83):

pode ser pensado como a respiração da significação, lugar de recuo necessário para que se possa significar, para que o sentido faça sentido. É o silêncio como horizonte, como iminência de sentido. Esta é uma das formas de silêncio, a que chamamos silêncio fundador: silêncio que indica que o sentido pode sempre ser outro. Mas há outras formas de silêncio que atravessam as palavras, que "falam" por elas, que as calam.

Os efeitos de sentido, assim, diferenciam-se, em uma mesma situação, tanto pelos silêncios quanto pelas escolhas de linguagem. Pode-se dizer, por exemplo, que um grupo de integrantes do movimento sem-terra "ocupou" ou "invadiu" determinado lugar; ao optar-se por um dos verbos, sentidos diversos são produzidos. Silencia-se uma forma ao se pronunciar outra. Portanto, "não é tudo que não foi dito, é só o não dito relevante para aquela situação significativa" (ORLANDI, 2012, p. 83). A autora formula ainda que há um espaço de interpretação onde o sujeito se move entre o que é dito e o que não é dito.

Também é importante apontar a questão da memória que se relaciona com a linguagem e com a história. A memória se firma no que faz sentido à formação social, produzindo, segundo Venturini (2008), a aproximação de sujeitos e grupos através de perspectivas identitárias em comum. 


\section{$\gamma_{\text {Rizoma }}$}

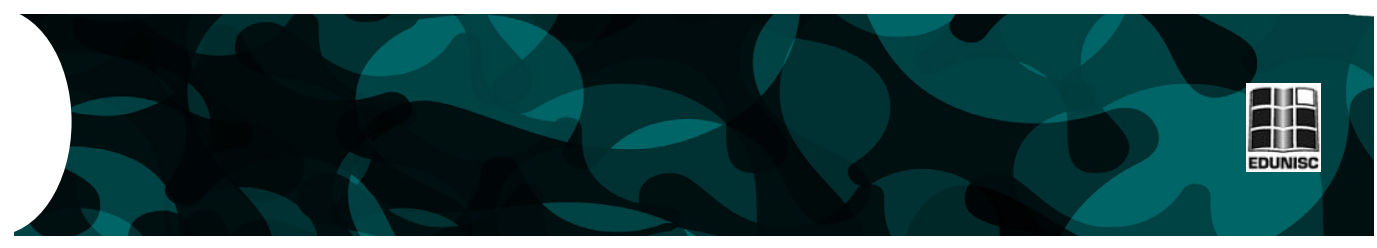

\section{Sujeito, Língua e História}

A troca de palavras envolve a imagem que se tem de quem pronuncia a fala, do sujeito interlocutor e também do objeto do discurso que, segundo Orlandi (2012), faz parte de um jogo imaginário. A imagem tem muita força sobre aquilo que é pronunciado, pois o imaginário faz parte da constituição da linguagem. "Com a análise do discurso podemos atravessar este imaginário que condiciona os sujeitos em suas discursividades e, explicitando o modo como os sentidos estão sendo produzidos, compreender melhor o que está sendo dito" (ORLANDI, 2012, p. 42).

Os discursos apresentados nos telejornais são submetidos às regras das emissoras a que pertencem, porém não deixam de transparecer a essência histórica dos sujeitos autores. Segundo Scherer, o acontecimento tem força como marca de significação carregada de sentidos, pois estes "se deslocam e se articulam em uma multiplicidade na historicização do acontecimento" (SCHERER, 2007, p. 350). Para a autora, a constituição do sujeito dá-se pela língua e pelo lugar ocupado nela, mas "o lugar ocupado por ela constitui-se pelo lugar que ocupamos, também fisicamente neste espaço" (SCHERER, 2007, p. 351).

As rupturas e transformações de sentidos fazem parte da realidade da história. Para Venturini (2008, p. 76), quando esta história privilegia a memória como conhecimento, "muitas vezes apaga os traços da memória dita involuntária, especialmente quando estes traços visibilizam memórias apagadas ou silenciadas que não interessam oficializar ou tornar de domínio público". Diante disso, segundo Scherer (2007), a constituição do sujeito vai acontecendo na língua pela sua história e na própria essência.

\section{Observações e Análises}

A partir da importância dos apresentadores no telejornal, vamos nos focar na observação da postura e dos discursos desses sujeitos na cobertura da tragédia da Chapecoense. Para isso, buscaremos apoio na Análise do Discurso, que possibilita entender o que o texto diz, como ele diz e também o porquê de estar dizendo. O discurso posicionado sob análise permite que observemos a relação entre os campos da língua e da sociedade (GREGOLIN, 1995).

A análise da movimentação dos efeitos de sentidos observados parte da definição do corpus: a edição do Jornal Nacional do dia 29 de novembro de 2016, data do acidente, que apresenta a cobertura do fato, perpassada pela interpretação dos apresentadores Giuliana Morrone e Heraldo Machado, que estavam à frente do telejornal, na semana da tragédia, em substituição aos titulares.

A presente análise aborda as expressões que marcam cada sujeito na condição de apresentador de telejornal (identificação da postura, discursos, silêncios, construção de memória e ideologia) e que aparecem representadas em diversas situações no decorrer da edição do JN. Em relação à ideologia, Pêcheux (1990) chama de "formação ideológica" ou 
"condições de produção do discurso", pois para ele as diversas formações ideológicas sociais correspondem a uma formação discursiva específica, ou seja, aquilo que é possível dizer em uma sociedade, em determinada época. De acordo com Althusser (s.d.), há uma sensação de liberdade quando os sujeitos diante de um determinado lugar na sociedade são interpelados pela ideologia. O discurso é, portanto, um dos aspectos materiais da ideologia.

$\mathrm{Na}$ edição que foi ao ar no dia 29 de novembro, a apresentadora Giuliana Morrone usava saia preta e camisa branca. Já Heraldo Pereira estava vestido com tons de cinza e azul. As vestimentas dos dois foram marcadas pela sobriedade, mostrando que o JN daquele dia estava em clima de consternação.

Logo após a escalada ${ }^{5}$, a cabeça ${ }^{6}$ da primeira reportagem sobre a tragédia demonstra que a apresentadora Giuliana Morrone ficou visivelmente emocionada ao falar dos colegas jornalistas que morreram no acidente:

GIULIANA MORRONE - Setenta e uma pessoas morreram. Dezenove eram jogadores. Jornalistas de vários veículos que acompanhavam a equipe também estão entre os mortos, inclusive, colegas queridos nossos, da TV Globo, e da nossa afiliada, a RBS.

A fala de Giuliana caracteriza os colegas como "queridos", mostrando traços de sensibilidade em relação aos jornalistas mortos e convocando os espectadores a olharem com carinho o trágico fato. Mas, há um silenciamento em relação aos jornalistas de outras emissoras, visto que o discurso da apresentadora dá destaque apenas aos colegas da Rede Globo e da RBS TV. Neste ponto, fica evidente a institucionalidade da Rede Globo, pois mesmo diante de um fato trágico dessa dimensão, os integrantes da empresa são apontados com destaque, enquanto os demais jornalistas mortos ficam no espaço de silenciamento. Vale destacar aqui que o discurso só faz sentido para alguém quando este o reconhece como parte de uma formação discursiva. Segundo Fiorin (1990, p. 177), "o discurso deve ser visto como objeto linguístico e como objeto histórico".

Percebe-se também, nos silenciamentos dos jornalistas, que a institucionalidade trazida é uma forma de aproximação do telejornal e dos apresentadores com a tragédia, mostrando que eles também foram afetados, que perderam pessoas próximas. Portanto, para além da institucionalidade, identifica-se também a necessidade que eles têm de mostrar que compartilham do sofrimento, através da morte de colegas.

No decorrer do programa, uma reportagem sobre os jornalistas mortos é apresentada. Giuliana Morrone, na cabeça da matéria, novamente enfoca os profissionais da Rede Globo: "Vinte e um jornalistas estavam no avião que caiu na Colômbia. Vinte deles morreram nessa tragédia. Eles viajavam com os jogadores para contar para todo o país a última etapa dessa campanha histórica da Chapecoense na Copa Sul-Americana. Entre os 20 mortos, três eram da TV Globo e cinco do grupo RBS". A apresentadora volta a ser guiada por questões de institucionalidade.
5 É o resumo das principais matérias do telejornal com o propósito de atrair e manter a atenção dos telespectadores desde o início do programa. Abrem os noticiários com textos e imagens curtas (YORKE, 2006).

6 A cabeça é o segmento da notícia apresentado pelo âncora do telejornal e corresponde ao início da matéria, trazendo as principais informações sobre o fato (REZENDE, 2000). 

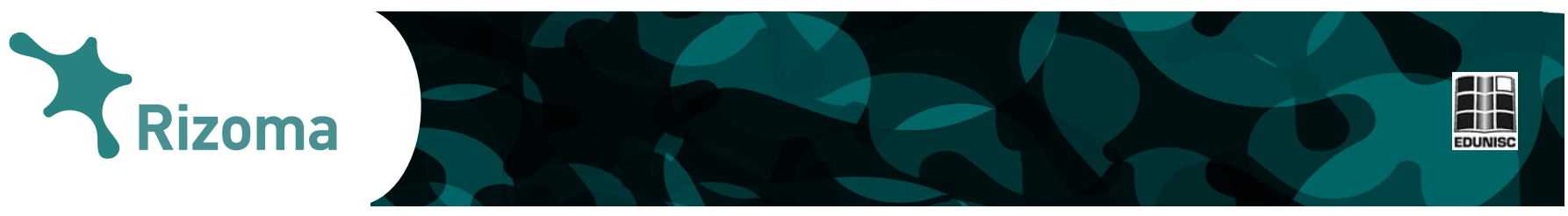

Só no final da reportagem, Heraldo Pereira, em cabeça para outra reportagem, salienta: "Na relação dos jornalistas que estavam no voo da

${ }^{7}$ Enquadramento feito dos joelhos para cima. Chapecoense, havia ainda outros 12 companheiros de outras emissoras".

Figura 1 - Giuliana Morrone durante a apresentação do JN de $29 / 11 / 2016$

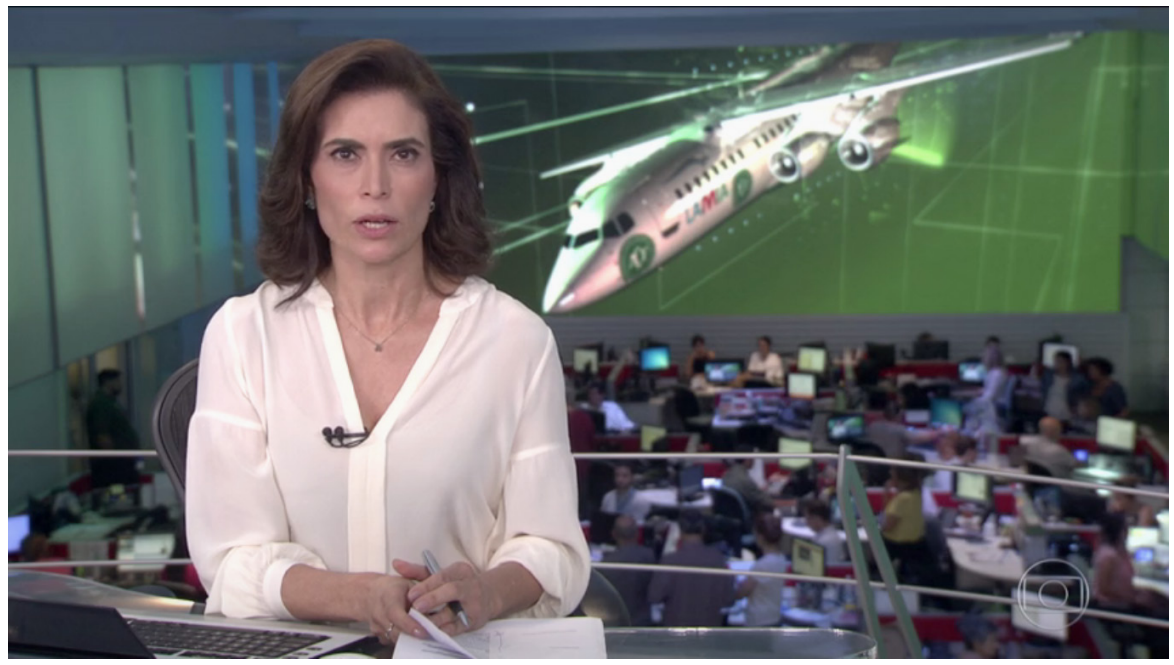

É no discurso que aparecem os valores sobre os quais o texto se apoia. Nas notícias, o enunciador normalmente constrói o efeito de objetividade, mantendo a imparcialidade através do afastamento entre enunciação e discurso. Para isso: "os recursos utilizados são o uso da $3^{\text {a }}$ pessoa, no tempo do 'então' e no espaço do 'lá', e o uso do discurso direto para garantir a verdade" (GREGOLIN, 1995, p. 19).

Ao chamar a correspondente Lilian Telles, que estava na Colômbia, a apresentadora é enquadrada em plano americano ${ }^{7}$, olhando de forma consternada para o telão com a imagem da repórter. A face entristecida de Lilian também é enfatizada. Ela fala com muita seriedade sobre as informações do acidente.

Figura 2 - Giuliana Morrone em contato com Liliam Telles

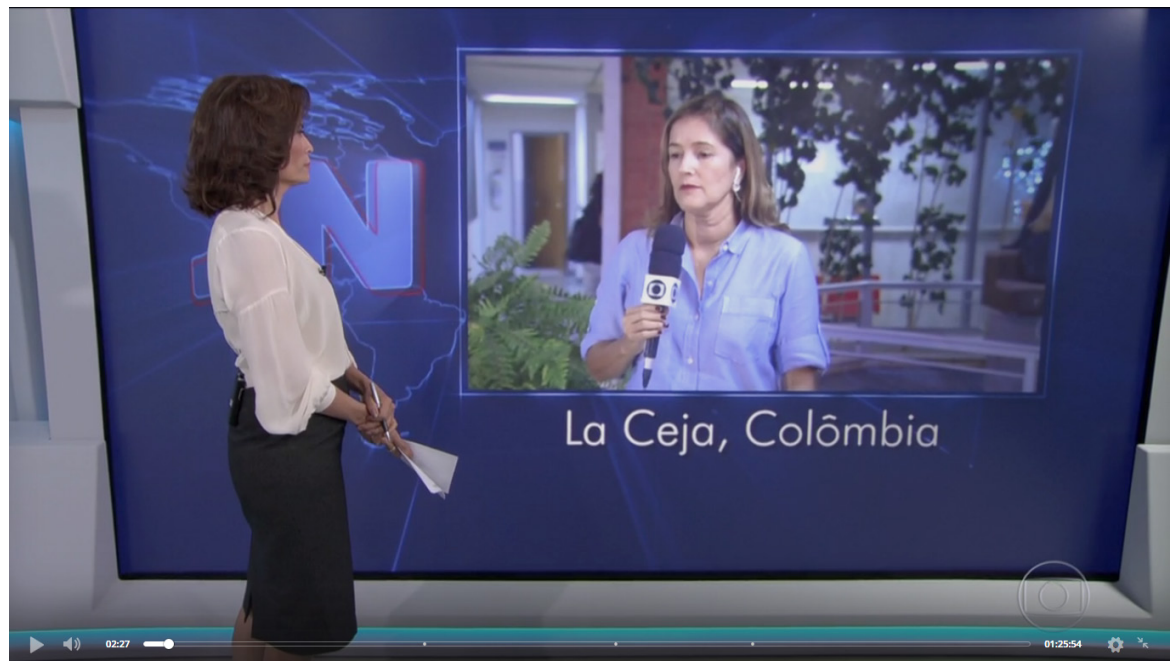



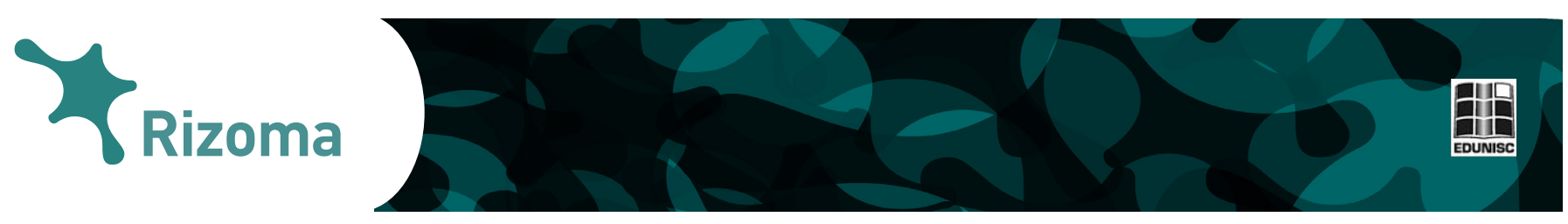

Morrone, ao fazer a cabeça da segunda reportagem da edição do JN do dia 29 de novembro de 2016, ressalta a empolgação dos jogadores com a viagem à Colômbia: "Antes da viagem, integrantes da delegação da Chapecoense divulgaram vídeos. Nas gravações, eles falam da alegria imensa de disputar uma final". A apresentadora fala de forma enfática sobre a alegria dos jogadores, mostrando ao público a importância do jogo para o time da Chapecoense. Porém, o efeito de sentido deixa de lado a relevância da partida e marca o contraste que isso representa com o destino da viagem, que acabou em tragédia. Diante disso, identifica-se o contraste de emoções: o que era alegria virou tristeza; o efeito de baque, choque ganha destaque.

$\mathrm{Na}$ mesma edição do $\mathrm{JN}$, os apresentadores receberam o locutor Galvão Bueno no estúdio, o qual falou sobre suas viagens à Colômbia e sobre $\mathrm{o}$ aeroporto em que a delegação da Chapecoense iria aterrissar. $\mathrm{O}$ tom da entrevista foi marcado pela seriedade, tanto dos dois apresentadores, como do comentarista. A conversa com Galvão Bueno é uma forma de remissão à emissora. Galvão Bueno não é um agente especializado em aeroportos. Ele falou sobre o tema por ser um profissional da rede Globo ligado aos esportes. Galvão voltou a ser chamado à bancada do telejornal no decorrer do programa, enfocando, na sua participação, a solidariedade. Como acentuou Giuliana: "Galvão, nestas horas tão difíceis, a solidariedade vem de todas as partes".

Ao longo dessa edição do $\mathrm{JN}$, enquanto um dos apresentadores chamava a próxima reportagem sobre a queda do avião, o outro mantinha a perspectiva de consternação e de seriedade. A postura dos dois foi marcada por uma forma sóbria de conduzir o programa.

Os apresentadores, ao noticiarem determinadas abordagens decorrentes da tragédia, como a dor dos familiares dos falecidos e dos moradores da cidade de Chapecó, deram ênfase a algumas expressões específicas. Giuliana, ao falar do sentimento de tristeza que tomou conta da cidade de Chapecó, reitera a expressão "grande dor", tentando evidenciar ao público as grandes dimensões de consternação e de comoção na cidade catarinense.

GIULIANA MORRONE - $A$ cidade de Chapecó amanheceu de luto. $O$ que era um sonho para a população de pouco mais de 200 mil habitantes se transformou numa grande dor.

Logo após a fala de Morrone, enfatizando a expressão "grande dor", o repórter Ricardo Von Dorff é chamado. A reportagem produzida por Von Dorff começa com pessoas da cidade comentando sobre o sofrimento e a incredibilidade em relação à tragédia. A fala da apresentadora foi confirmada pelas expressões das fontes destacadas na matéria. Após a reportagem, os apresentadores voltam e destacam a dor da perda dos jogadores e dos muitos sonhos que foram destruídos. Os dois falam conversando entre si. E a apresentadora mexe a cabeça, mostrando estar consternada.

HERALDO PEREIRA - Em Chapecó e pelo Brasil, os parentes das vítimas não conseguiam acreditar na tragédia.

GIULIANA MORRONE - E nessa tristeza toda, lamentava o fim de muitos sonhos.

Rizoma, Santa Cruz do Sul, v. 6, n. 1, p. 55, agosto, 2018 

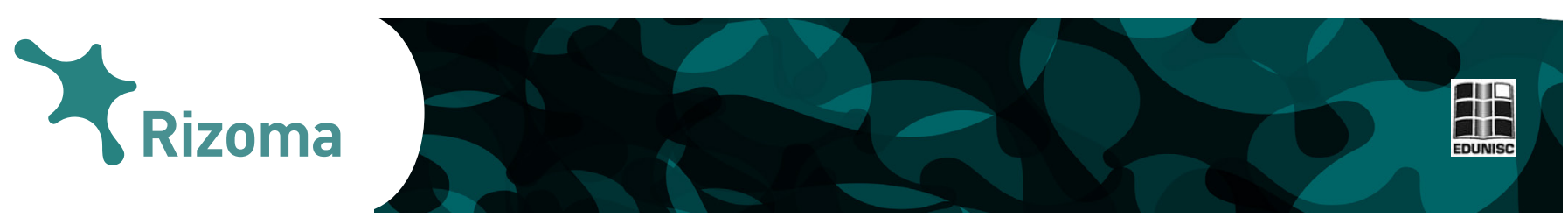

A comunicação entre os apresentadores aciona a ideia de que os dois estão em interlocução para reiterar as questões enfatizadas pelo JN . A emoção foi, mais uma vez, evocada nos momentos finais da edição do Jornal Nacional em estudo. Na voz dos apresentadores, ela foi destacada:

GIULIANA MORRONE - Tragédias como a da Chapecoense marcam o esporte mundial. Mas, por trás do sentimento da equipe que se vai, ficam as memórias dos homens, pais, filhos, maridos que para sempre serão lembrados.

HERALDO PEREIRA - Um embrulho, um bilhete. E o atacante Thiaguinho comemora com os companheiros o gol mais bonito. Ele acabava de saber que seria pai pela primeira vez aos 22 anos. As imagens foram feitas na semana passada, na concentração da Chapecoense.

No contexto de destaque às emoções, as memórias deixadas pelos falecidos são evocadas. Episódios importantes da vida dos atletas ganham espaço. E o JN destaca que além da morte de grandes atletas, ocorreu a perda de pessoas, as quais têm história.

A edição do dia 29 de novembro é finalizada com uma homenagem da redação do JN às vítimas do acidente. Neste caso, a Globo ocupa um lugar de compartilhamento da dor de todo um país. A homenagem é marcada por uma salva de palmas da equipe do telejornal.

Diante da descrição dos principais momentos apresentados e representados no JN pelos seus apresentadores sobre a queda do avião que transportava a equipe da Chapecoense, percebemos que o enunciador tenta fazer com que o enunciatário acredite na verdade do discurso, pois "há um contrato de veridicção entre enunciador e enunciatário. Por isso, o enunciador constrói no discurso todo um dispositivo veridictório, espalha marcas que devem ser encontradas e interpretadas pelo enunciatário" (GREGOLIN, 1995, p. 19). São as estratégias discursivas que formam o texto por meio de pressupostos e de subentendidos. É nos subentendidos que se torna possível dizer algo sem assumir a responsabilidade de ter dito. Segundo Gregolin (1995), o contexto sócio-histórico está presente neste sentido, pois para um texto ser subentendido é necessário que o enunciador e enunciatário partilhem um conhecimento que permite compreender os significados.

\section{Considerações finais}

Em um telejornal, os apresentadores têm papel fundamental na condução das informações e na produção de sentidos sobre elas.

Em coberturas de tragédias - como neste caso específico de um acidente com dezenas de mortes -, o delineamento das reportagens e a forma como elas são apresentadas convocam diversos sentidos e demarcam diferentes pontos que estão envolvidos no discurso, como os silenciamentos, a remissão à memória e o destaque a alguns sentidos preferenciais.

No caso da cobertura do Jornal Nacional do acidente com o avião 

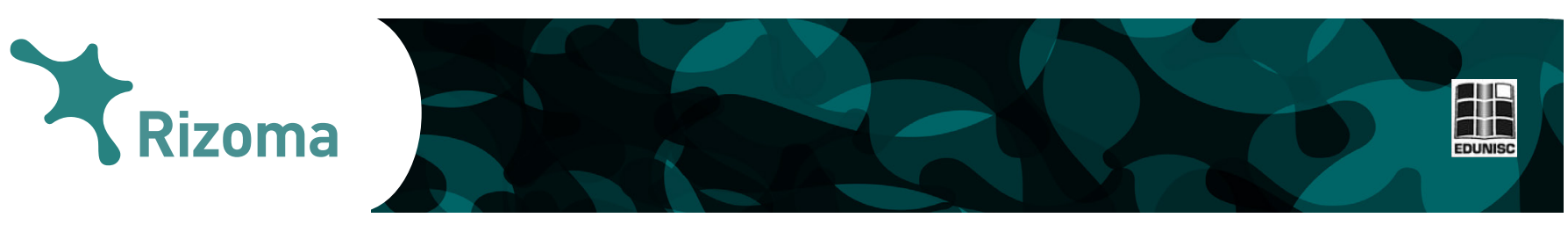

da Chapecoense, Heraldo Pereira e Giuliana Morrone foram fundamentais para que diversos sentidos fossem acionados nos espectadores, como das dimensões da tragédia e da dor de familiares e pessoas próximas às vítimas, da tristeza de um país frente à perda de um time de futebol e de profissionais do jornalismo.

Giuliana e Heraldo, no decorrer da edição analisada, denotaram as emoções daquele momento. E tiveram olhares que, muitas vezes, foge ao modo tradicional de levar um acontecimento ao ar em um telejornal. Ao transparecerem emoções, os dois apresentadores fizeram rupturas em relação à postura indicada em alguns manuais de redação de telejornalismo e acentuaram a perspectiva de que os telejornais, na atualidade, estão cada vez mais tentando aproximação com o público.

Claro que não podemos deixar de destacar que a manifestação de emoções na edição analisada beirou à espetacularização da notícia. E que houve uma forma acentuada de demonstração do lado emocional da tragédia.

Diante disso, concordamos com Gregolin (1995) que analisar o discurso implica em tentar entender a construção do sentido de um texto e sua articulação com a história e a sociedade que o produziu. Para entender o discurso é preciso levar em consideração seus aspectos linguísticos e históricos. Dessa forma, o artigo permitiu fortalecer a reflexão sobre a estrutura e a construção do sentido do texto produzido pelos apresentadores do JN, na cobertura da tragédia com a equipe da Chapecoense, por meio de suas marcas estruturais e ideológicas.

\section{Referências}

ALTHUSSER, Louis. Aparelhos ideológicos do Estado. Lisboa: Almedina, s.d.

FECHINE, Ivana. Performance dos apresentadores dos telejornais:

a construção do éthos. Revista FAMECOS, Porto Alegre, n. 36, ago./2008.

FIORIN, José Luiz. Tendências da análise do discurso. Estudos Linguísticos, São Paulo, v. 19, 1990.

GREGOLI, Maria do Rosario Valencise. A Análise do Discurso: Conceitos e Aplicações. Alfa, São Paulo, n. 39, 1995.

MEMÓRIA GLOBO. Jornal Nacional. Disponível em: http://memoriaglobo. globo.com/programas/jornalismo/telejornais/jornal-nacional.htm. Acesso em: 28 set. 2016.

ORLANDI, Eni Puccinelli. Análise de discurso: princípios e procedimentos. Campinas: Pontes, 2012.

. A questão do assujeitamento: um caso de determinação histórica.

Revista Eletrônica de Jornalismo Científico, São Paulo, v. 89, p. 2, 2007. 

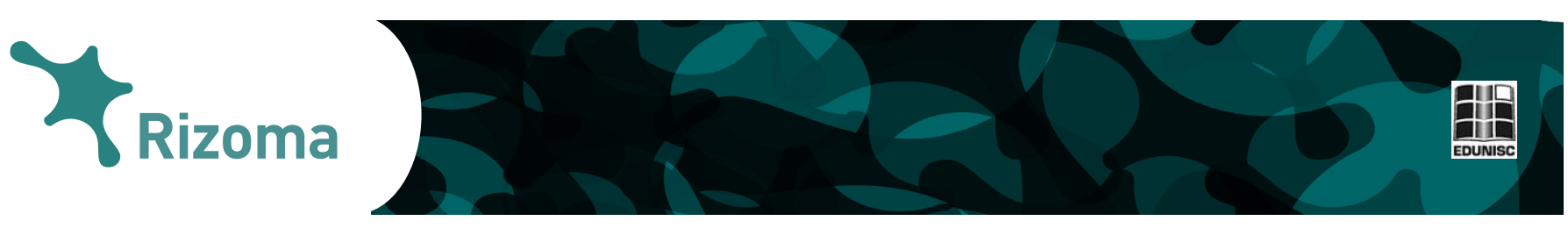

- Michel Pêcheux e a Análise de Discurso. Estudos da

Lingua(gem), Vitória da Conquista, jun/2005.

As formas do silêncio: no movimento dos sentidos. Campinas:

Editora da UNICAMP, 1997.

Interpretação: autoria, leitura e efeitos do trabalho simbólico.

Petrópolis: Vozes, 1996.

PÊCHEUX, Michel. Apresentação da AAD. In: GADET, F., HAK, H. Por uma análise automática do discurso (Uma introdução à obra de Michel Pêcheux). Campinas: Pontes, 1990.

PETRI, Verli. A diferença no discurso e o discurso da diferença. In: BRAGANÇA, S.; PARKER, M. (Orgs.). Igualdade nas diferenças: os significados do "ser diferente" e suas repercussões na sociedade. Porto Alegre: UERGS, 2009.

SCHERER, Amanda Eloína. A constituição do eu e do outro pela interpelação da língua pela língua na história do sujeito. In FERREIRA, M. C; INDURSKY, F. (Orgs.). Análise do Discurso no Brasil: mapeando conceitos, confrontando limites. São Carlos: Claraluz, 2007.

VENTURINI, Maria Cleci. Rememoração/Comemoração: prática discursiva de constituição de um imaginário urbano. 2008. Tese (Programa de Pós-Graduação em Letras - Mestrado e Doutorado) Universidade Federal de Santa Maria, Santa Maria, 2008.

YORK, Ivor. Telejornalismo. São Paulo: Roca, 2006. 